Review

\title{
A Review on the Behavior of 308L Cladding Material and Their Corrosion in Nuclear Power Plants
}

\author{
Hassan Tukur*, Lu Yonghao* \\ National Center for Material Service Safety, University of Science and Technology, Beijing, China \\ P.R. \\ *E-mail: tingilin@yahoo.com, $\underline{\text { lu_yonghao@mater.ustb.edu.cn }}$
}

doi: $10.20964 / 2020.01 .67$

Received: 17 June 2019 / Accepted: 20 November 2019 / Published: 30 November 2019

\begin{abstract}
The shell materials in the main plants (pressure vessels, voltage regulators and steam generators) for nuclear equipment sometimes adopt surfacing welding on low alloy steel forging 308L austenitic stainless-steel welding layer manufacturing. Therefore, austenitic stainless-steel welding layer has an important influence in the nuclear power demanding service environment under the shell materials' performance for safe and effective operation. At the same time, effects of thermal aging cause a decline in performance of the stainless-steel surfacing layer, due to long service life of nuclear power plants. This is a key factor in the service safety of nuclear power plants. Several studies have been conducted on this phenomenon. In this paper, a review of the different studies on the microstructure, thermal aging behavior and its effect on oxidation behavior of domestic 308L stainless-steel surfacing layer is presented. Articles on small punching test and in-situ tensile test for deformation fracture behavior characteristics in phases of the microstructure of surfacing layer before and after thermal aging were reviewed. Also, researches on experiments combined with X-ray diffraction and X-ray photoelectron spectroscopy for detection of corrosion weight gain or loss, and oxidation film formed by the surfacing layer under high temperature and pressure, were presented. Through the review of experimental results in several articles, the laws and mechanisms of the changes in the microstructure, mechanical damage and high temperature water oxidation behavior of domestic surfacing materials $308 \mathrm{~L}$ were clarified. The correlation between the property damage and microstructure evolution was revealed. Research gaps were brought out and conclusions as well as recommendations for further research were given.
\end{abstract}

Keywords: 308L stainless steel, weld surfacing, thermal aging, microstructure, mechanical property, oxidation behavior 
(C) 2020 The Authors. Published by ESG (www.electrochemsci.org). This article is an open access article distributed under the terms and conditions of the Creative Commons Attribution license (http://creativecommons.org/licenses/by/4.0/). 